\title{
CD49 Expression in Chronic Lymphocytic Leukemia B-Cell and Non-Hodgkin Lymphoma
}

\author{
DALIA IBRAHIM, M.D.* and ABEER FAROUK, M.D.** \\ The Departments of Physiology* and Clinical Pathology**, Suez Canal University, National Cancer Institute
}

\begin{abstract}
Background: B-Chronic lymphocytic leukemia (B-CLL) is a monoclonal disorder which is characterized by the accumulation of small mature-appearing B lymphocytes in the blood, bone marrow, and lymphoid tissues. Several reliable prognostic markers were found to be capable of predicting the progression and outcome of the disease from its early stages. these markers including age, sex, lymphocyte morphology and number, lymphocyte doubling time (LDT), serum factors and recently immunophenotyping and cytogenetic findings.
\end{abstract}

CD49d expression consistently identifies a subgroup of CLLwhich is characterized by poor outcome in many recent studies. These observations, recommended its use as a new marker that could be included in the initial prognostic assessment of all survival in patients with CLL

Aim of Study: The aim of this work is to assess the expression pattern of CD49 in patients with (B-CLL) and to evaluate their correlation with different clinical and laboratory data as well as the relation to disease staging and progression. We also aim to find if there is a difference in the expression between patients with B-CLL and B-cell non-Hodgkin lymphoma (B-NHL).

Material and Methods: This study was done at National Cancer Institute, during the period from January 2018 to March 2018, conducted on 6 B-CLL patients and 5 NHL patients who were evaluated for CD49 to detect their role and specificity in B-CLL. Patients were selected for the study on the basis of standard clinical, hematological and immunophenotypic criteria for diagnosis of B-CLL, Their ages ranged from 42-79 years, and 5 healthy, hematologically normal individuals, were chosen as control group. Measuring of CD49 by flow cytometry (Coulter EPICS-XL, USA)

Results: In this study, there was a high significant increase in CD49d expression in CLL cases ( $p .004)$ when comparing with control group, A significant correlation was found between positive CD 49d pts. and Rai staging ( $p 0.015)$ in which there was an advanced Rai stage (III, IV) among positive CD49d patients in comparison to negative CD49d patients. While for LDH, its level was high significant ( $p .005)$ among positive CD49d patients compared to negative CD49d patients.

Correspondence to: Dr. Dalia Ibrahim, The Department of Physiology, Suez Canal University, National Cancer Institute
High significant difference was found between the NHL group and control as regards expression of CD49d ( $p .0001)$

Most NHL (95\%) expressed positive CD 49d while only $58 \%$ of CLL expressed positive CD $49 \mathrm{~d}$ which is of statistically significant difference $(p<0.05)$.

Conclusion: The present study confirmed that CD49d expression is a powerful prognostic parameter in patients with CLL. when correlates with RAI stage and LDH level. So CD49d showed association with poor disease outcome in CLL patients. CD49d showed a significant high expression in NHL Thus CD49d is not specific for CLL. But it could be used as a prognostic marker.

Key Words: Chronic lymphocytic leukemia B-cell - NonHodgkin lymphoma CD49.

\section{Introduction}

B-CLL is a monoclonal disorder characterized by the progressive accumulation of functionally incompetent mature looking, monoclonal B lymphocytes in blood, bone marrow (BM), lymph nodes and spleen/liver [1]

CLL follows an extremely variable clinical course with overall survival times ranging from months to decades. Some patients have no or minimal signs and symptoms during their disease course and also have a survival time similar to age-matched controls. But some patients experience rapidly deteriorating blood counts, organomegaly and suffer from symptoms and signs at diagnosis or soon, thereafter necessitating therapy [2] .

A large number of prognostic factors help predict the outcome of the patients with B-CLL. These include stage, cell morphology, cytogenic abnormalities and serum factors such as B2 microglobulin [3]

Typical feature of CLL is the presence of smudge (basket) cells on the smears, reflecting 
fragility and distortion during preparation of the smear on the glass slide. This is rarely present in other B-cell diseases, even in the presence of lymphocytosis [4].

Atypical CLL represents around 15\% of CLL cases and comprises two subtypes as follows: (i) CLL with increased prolymphocytes (>10\%), also designated CLL/PLL.(ii) Atypical CLL with cells having morphological features suggestive of lymphoplasmacytic differentiation and/or the presence of cleaved cells; this subgroup was designated by the FAB as mixed-cell type [5].

The decision to treat is guided by the stage of the disease, the presence of symptoms, and the disease activity. Patients in earlier stages (Rai 0II, Binet A and B) are generally not treated but monitored with 'watch and wait' [6].

New aspects of the updated IWCLL-guidelines in comparison to the 1996-version published by the National Cancer Institute Working Group (NCIWG) in 2008:

- A peripheral blood lymphocyte counts of greater than $5 \times 10 \%$ L for a duration at least 3 months. With less than $55 \%$ of the cells being atypical. The cells should have B cell-specific differentiation antigens (CD19, CD20, and CD23), either $\kappa$ or $\lambda$ Chain surface Ig, confirming monoclonicity; low-density surface Ig and B-cell PLL don't express CD5 in half of the cases and typically express high levels of surface Ig and CD20.

- Bone marrows aspirate showing greater than $30 \%$ lymphocytes.

- Role of cytogenetics and FISH analysis for the detection of unfavourable prognostic factors.

- CT scans are recommended to assess lymphadenopathy in CLL patients only within clinical trials, in order to allow an optimal response assessment.

- Staging examinations to assess the remission status after any therapy are recommended to be performed not earlier than 3 months (former criteria: 2 months) and not later than 6 months (in case of persistant cytopenias) after treatment completion $[\mathbf{7 , 8}]$.

CD49d is an alpha subunit. It makes up half of the $\alpha 4 \beta$ 1-lymphocyte homing receptors [9]. It's functionally acting as an adhesion molecule mediating cell to cell and cell to extracellular matri $\mathrm{x}$ interactions so mediates the interaction of lymphocytes with micro-environmental components which reduces both spontaneous and drug-induced apoptosis [10]. CD49d expression is suggested to be independent predictor of survival in patients with B-CLL [11]

\section{Patients and Methods}

This study was conducted on 6 B-CLL patients and 5 NHL patients who were evaluated for CD49 by flowcytometry to detect their role and specificity in B-CLL who were attending to National Cancer Institute, during the period from January 2018 to March 2018, the patients were selected for the study on the basis of standard clinical, hematological and immunophenotypic criteria for diagnosis of B-CLL. Their ages ranged from 42-79 years, and 5 healthy, hematologically normal individuals, were chosen as control group.

All patients and controls were subjected to the following except for (4\& 5) were done for patients only:

- Full history taking and clinical examination stressing on the presence of lymphadenopathy, splenomegaly, hepatomegaly, presence of infection and presence of symptoms and signs of anemia and/or thrombocytopenia.

- Abdomino-plevic ultrasound for lymphadenopathy and/or organomeglay.

- Laboratory investigation including:

- Complete blood count (CBC).

- Leishman-stained peripheral blood (PB) smears examination laying stress on lymphocyte $\%$ and absolute lymphocyte count.

- Bone marrow (BM) aspiration with examination of Leishman-stained smears.

- Immunophenotyping of BM or whole PB. The following panel of monoclonal antibodies was used: (lymphoproliferative diseases panel) CD5, $\mathrm{CD} 19, \mathrm{CD} 23, \mathrm{CD} 38$ as well as $\kappa$ and $\lambda$ light chains labeled with either fluorescin isothiocyanate (FITC) or phycoerythrin (PE). Samples were considered positive for a marker if $\geq 20 \%$ of cells expressed that marker, except for CD38 positivity was considered $\geq 30 \%$ [12]

- Measuring of CD49 by flow cytometry (Coulter EPICS-XL, USA), Anti CD49d was added to tubes of sample and lysing solution, the tubes were centrifuged and Cells were suspended in $500^{\circ} \mathrm{L}$ PBS to be ready for acquiring data by the flow cytometer. 


\section{- Patients fulfilling all the following criteria were selected:}

a- PB persistent absolute lymphocytosis ( $>5$ $\mathrm{x} 109 / \mathrm{L})$ for at least 3 months period [13]

b- A characteristic immunophenotyping: CD5 +, $\mathrm{CD} 19+, \mathrm{CD} 23^{+}$, restricted $\kappa$ or $\lambda$ light chain expression and CD5/CD19 co-expression. Patients showing negative CD23 and CD5 expression were excluded.

- Lactate dehydrogenase enzyme concentration is measured by fully automated machine (Synchron CX4).

The results were expressed as:

The percentage of lymphocytes carry in CD49d within the population of lymphocytes.

\section{Statistical analysis:}

SPSS statistical software was used applying appropriate statistical method. Data are presented as mean \pm SD. Differences between two groups were assessed by the Student's paired $t$-test, chi square test Comparison among the two groups was performed by one way analysis of variance. Chi square test was also used. $p$-value $<0.05$ was considered significant.

\section{Results}

Laboratory data of the studied CLL patients (Table 1):

As for the laboratory data, the TLC ranged from 4.8 to $775.0 \times 109 / \mathrm{L}$ with a mean of 137.2 $\mathrm{x} 109 / \mathrm{L} \pm 188.3$, the relative lymphocytic count ranged from 39.5 to $98 \%$ with a mean of $78.4 \pm 20.5$. The $\mathrm{Hb}$ concentration ranged from 5.0 to $15.1 \mathrm{~g} / \mathrm{dL}$ with a mean of $10.1 \mathrm{~g} / \mathrm{dL} \pm 2.9$, the platelets count ranged from 13.0 to $465.0 \times 109 / \mathrm{L}$ with a mean of 153.4.0 $\times 10^{9} / \mathrm{L} \pm 103.9$, The bone marrow lymphocytes ranged from 32 to $97 \%$ with a mean of $74.5 \% \pm 16.8$ and $\mathrm{LDH}$ concentration ranged from 151 to $1663 \mathrm{IU} / \mathrm{L}$ with a mean of $694.2 \mathrm{IU} / \mathrm{L} \pm 351.1$.

CD49d Expression by flow cytometry in control cases:

CD49d expression is negative in all control cases $(100 \%)$ with a mean $9.06 \pm 6.82$ SD (Table 2).

\section{CD49d Expression by flow cytometry in CLLcases:}

Values $\geq 30 \%$ were considered positive expression of CD49d and designated while those below this level were considered negative. According to this cut off value (58.3\%) of cases had positive CD49d expression, their values ranged from 30.0 to 98.3 and (41.7\%) of cases had negative CD49d expression, their values ranged from 1.7 to 29.1 (Table 3).
By comparing expression of CD49d in CLL cases and control group, there was a high significant increase in CD49d expression in CLL cases ( $p$.004). (Table 4).

Comparison between positive and negative CD49d CLL cases as regards to clinical and lab data: (Table 5): Their age ranges from 42 to $79.78 .6 \%$ of patients with positive CD49d expression had lymphadenopathy $(78.6 \%)$ had splenomegaly and $(42.9 \%)$ had hepatomegaly, while in negative cd $49 \mathrm{~d}$ patients (60\%) had lymphadenopathy, $(60.0 \%)$ had splenomegaly, and (50\%) had hepatomegaly.

There was no significant difference between positive CD49d CLL patients and negative CD49 d expression regarding age $(p .165)$. The same no significant difference between positive CD $49 \mathrm{~d}$ and lymphadenopathy $(p .326)$ or splenomegaly $(p 1.0)$ or hepatomegaly $(p 1.0)$. A significant correlation was found between positive CD 49d pts and Rai staging $(p$ 0.015) in which there was an advanced Rai stage (III, IV) among positive CD49d patients in comparison to negative CD49d patients.

No significance difference regarding lower $\mathrm{Hb}$ levels ( $p$ 0.093) or lower platelet count ( $p$.829) was observed in positive CD49d patients in comparison to negative CD49 d patients, the same regarding, high TLC count in peripheral blood ( $p$.939) or high lymphocytes in peripheral blood ( $p .301)$.

While for LDH, its level was high significant ( $p$ .005 ) among positive CD49d patients compared to negative CD49d patients. And a significant higher CD38 expression was found $(p 0.021)$ in positive CD49d compared to negative CD49d.

Table (1): Description of lab data among CLL cases.

\begin{tabular}{lllll}
\hline & Mean \pm SD & $\begin{array}{c}\text { Mini- } \\
\text { mum }\end{array}$ & $\begin{array}{c}\text { Maxi- } \\
\text { mum }\end{array}$ & Median \\
\hline TLC(x109/L) & $137.2 \pm 188.3$ & 4.8 & 775.0 & 85.9 \\
Lymph (\%) & $78.4 \pm 20.5$ & 39.5 & 98.0 & 87.5 \\
HB(g/dl) & $10.1 \pm 2.9$ & 5.0 & 15.1 & 9.9 \\
Plts (x109/L) & $153.4 \pm 103.9$ & 13.0 & 465.0 & 147.0 \\
BM lymph (\%) & $74.6 \pm 16.8$ & 32.0 & 97.0 & 77.0 \\
LDH (IU/L) & $694.2 \pm 351.1$ & 151 & 1663 & \\
\hline
\end{tabular}

Table (2): Description of CD49d data among controls.

\begin{tabular}{ccccc}
\hline & Mean \pm SD & Minimum & \multicolumn{2}{c}{ Maximum Median } \\
\hline CD49d & $9.06 \pm 6.82$ & .05 & 19.10 & 8.45 \\
\hline
\end{tabular}


Table (3): Description of CD49 d among CLL cases.

\begin{tabular}{ccccc}
\hline & \multicolumn{2}{c}{ Mean \pm SD Minimum } & \multicolumn{2}{c}{ Maximum Median } \\
\hline CD49d & $51.09 \pm 38.50$ & 1.70 & 98.30 & 56.15 \\
\hline
\end{tabular}

Table (4): Comparison between CLL and control groups as regard $\mathrm{CD} 49 \mathrm{~d}$.

\begin{tabular}{|c|c|c|c|c|c|}
\hline \multicolumn{2}{|c|}{ CLL } & \multicolumn{2}{|c|}{ Control } & \multirow{2}{*}{$p$} & \\
\hline $\begin{array}{c}\text { Mean } \\
\pm \text { SD }\end{array}$ & Median & $\begin{array}{c}\text { Mean } \\
\pm \text { SD }\end{array}$ & Median & & \\
\hline
\end{tabular}

CD49d $51.09 \pm 38.5065 .159 .06 \pm 6.828 .45 \quad .004$ HS

Table (5): Comparison between clinical data among positive and negative CD49d patients.

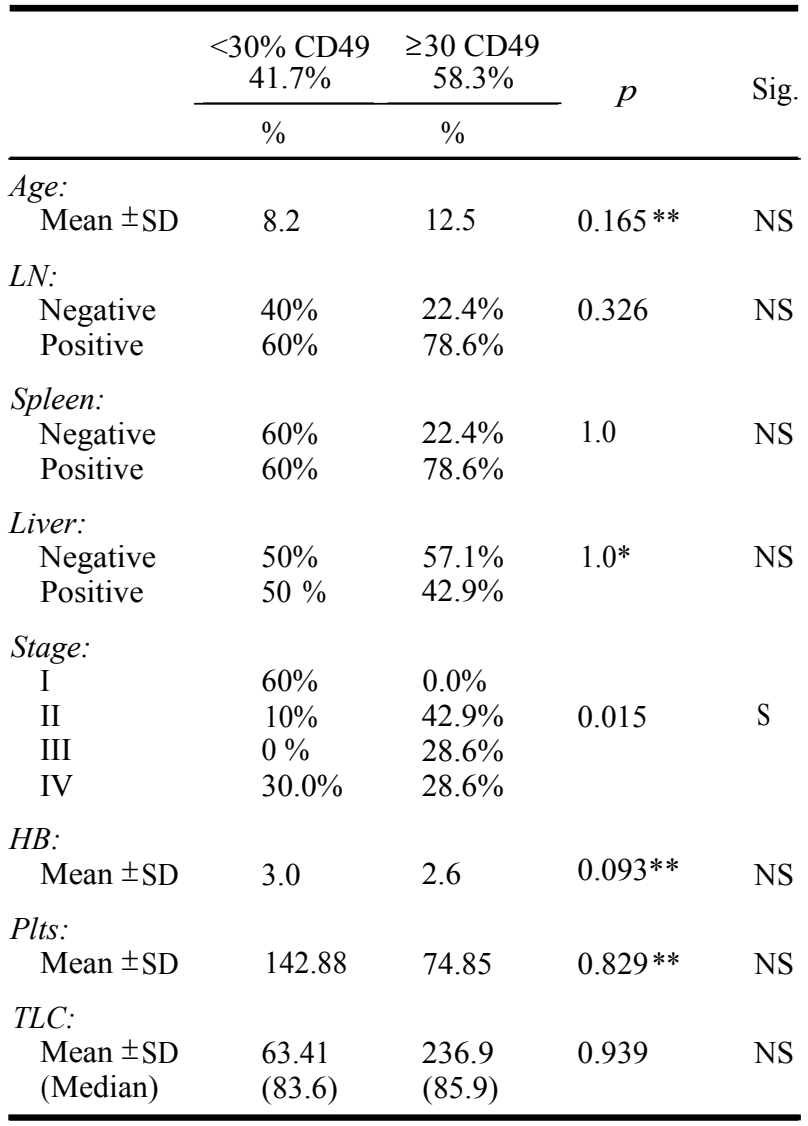

\section{Laboratory data of the studied NHL patients} (Table 6):

As for the laboratory data, the $\mathrm{Hb}$ concentration ranged from 4.0 to $12.6 \mathrm{~g} / \mathrm{dL}$ with a mean of $9.7 \mathrm{~g} / \mathrm{dL}$ \pm 2.4 , the platelet count ranged from 48.0 to 438.0 $\mathrm{x} 10^{9} / \mathrm{L}$ with a mean of $171.2 \times 10^{9} / \mathrm{L} \pm 111.1$, the TLC ranged from 1.2 to $138.0 \times 10^{9} / \mathrm{L}$ with a mean of 41.9 $\mathrm{x} 10^{9} / \mathrm{L} \pm 40.7$, the relative lymphocytic count ranged from 12 to $95 \%$ with a mean of $64.4 \pm 26.1$. The bone marrow lymphocytes ranged from 3.0 to $95 \%$ with a mean of $53.7 \% \pm 26.2$.
CD49d Expression by flow cytometry in NHL cases (Table 7):

Cd49d is positive in NHL cases with a mean of $78.68 \pm$ SD2 1.84

There was a high significant differnence was found between the NHL group and control as regards expression of CD49d ( $p$.0001).

Based on value of $30 \%$, cases of NHL are divided into 2 groups, positive CD49d expression ( $(\geq 30 \%)$ and they are $(95 \%)$, and the other group is negative CD49 d expression which (5\%).

Most NHL (95\%) expressed positive CD 49d while only $58 \%$ of CLL expressed positive CD $49 \mathrm{~d}$ which is of statistically significant difference $(p<0.05)$.

Table (6): Description of lab data among NHL cases.

\begin{tabular}{lllll}
\hline & Mean \pm SD & $\begin{array}{c}\text { Mini- } \\
\text { mum }\end{array}$ & $\begin{array}{c}\text { Maxi- } \\
\text { mum }\end{array}$ & Median \\
\hline HB(g/dL) & $9.7 \pm 2.4$ & 4.0 & 12.6 & 10.2 \\
Plts (x10 $/ \mathrm{L})$ & $171.2 \pm 111.1$ & 48.0 & 438.0 & 143.0 \\
TLC (x10 $/ \mathrm{L})$ & $41.9 \pm 40.7$ & 1.2 & 138.0 & 26.8 \\
Lymph (\%) & $64.4 \pm 26.1$ & 12.0 & 95.0 & 75.0 \\
BM lymph (\%) & $53.7 \pm 26.2$ & 3.0 & 95.0 & 58.0 \\
\hline
\end{tabular}

Table (7): Description of CD49d among NHL cases.

\begin{tabular}{ccccc}
\hline $\mathrm{N}=20$ & \multicolumn{2}{c}{ Mean \pm SD Minimum } & \multicolumn{2}{c}{ Maximum Median } \\
\hline CD49d & $78.68 \pm 21.84$ & 11.30 & 97.80 & 87.95 \\
\hline
\end{tabular}

Table (8): Comparison between NHL and control groups as regard CD49.

\begin{tabular}{|c|c|c|c|c|c|}
\hline \multicolumn{4}{|c|}{ Group } & \multirow{3}{*}{$p$} & \multirow{3}{*}{ Sig. } \\
\hline \multicolumn{2}{|c|}{$\mathrm{NHL}=5$ cases } & \multicolumn{2}{|c|}{ Control $=5$ cases } & & \\
\hline $\begin{array}{l}\text { Mean } \\
\pm \text { SD }\end{array}$ & Median & $\begin{array}{c}\text { Mean } \\
\pm \text { SD }\end{array}$ & Median & & \\
\hline
\end{tabular}

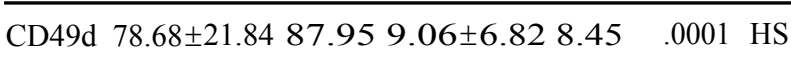

*Mann Whitney test.

Table (9): Comparison between NHL and CLL groups as regard CD49d.

\begin{tabular}{|c|c|c|c|c|}
\hline & $\begin{array}{c}\text { Non Hodgkin } \\
5 \text { cases }\end{array}$ & $\begin{array}{c}\text { CLL }= \\
6 \text { cases } \\
0\end{array}$ & \multicolumn{2}{|c|}{$\begin{array}{c}\text { Chi-square } \\
\text { test }\end{array}$} \\
\hline & $\%$ & $\%$ & $\mathrm{X} 2$ & $\begin{array}{c}p- \\
\text { value }\end{array}$ \\
\hline \multicolumn{5}{|l|}{ CD49d: } \\
\hline Negative & 5.00 & 41.67 & 5.989 & 0.006 \\
\hline Positive & 95.00 & 58.33 & & \\
\hline
\end{tabular}




\section{Discussion}

Patients with CLL have different clinical courses, some survive for a long time without therapy, while others progress towards more advanced stages and die despite aggressive treatment [12]

Several reliable prognostic markers were found to predict the progression and outcome of the disease from its early stages including age, sex, lymphocyte morphology and number, lymphocyte doubling time, serum factors, and, recently immunophenotyping and cytogenetic findings [13]

Potentially supportive interactions between CLL B cells and various nurturing environments are complex and involve cell-extracellular matrix interactions which is mediated in part through CD49d on CLL B-cells and VCAM- 1 expressed on marrow stromal cells, so CD49d can serve as signaling receptor that influences B-cell survival via up regulation of $\mathrm{Bcl} 2$ family members results in reduction of both spontaneous and drug induced apoptosis [14].

This study was conducted on 6 B-CLL patients and 5 NHL patients who were evaluated for CD49 expression by flowcytometry to detect their role and specificity in B-CLL.

As regards to CD49d expression, the present study showed that CD 49d expression in CLL patients were highly significant as compared to control groups ( $p$.004).

Rossi et al., [11] and Nuckel et al., [15] recommended $>30 \%$ as a cut off for CD49d expression.

On basis of cut off value ( $>30$ ), this study showed $(58.3 \%)$ with positive expression of CD49d (> $30 \%)$ and $(41.7 \%)$ of cases showed negative CD $49 \mathrm{~d}$, and they were both compared to the different studied parameters.

In the present study, there was insignificant correlation between positive CD $49 \mathrm{~d}$ and age $(p>$ 0.05). This was matched with study of Cro et al, [16] which showed no statistical significance in terms of age.

Also this study showed no statistical correlation between positive CD49d and lymphadenopathy, splenomegaly or hepatomegaly $(p>0.05)$.

This is in contrary to Cro et al., who mentioned in their study significant correlation between high CD49d and splenomegaly.
In the present study a statistically insignificant correlation between positive CD49d expression and lower $\mathrm{Hb}$ or platelet levels was found, the same for total leucocytic count and absolute lymphocytic count.

This was matched with study of Cro et al. which showed no statistical significance with the absolute number or morphology of lymphocytes in his study but, they found high significant correlation with low HB level.

This study showed a significant correlation between positive CD 49d pts and Rai staging (p 0.015 ) in which patients expressed positive CD $49 \mathrm{~d}$ ( $330 \%$ ) presented more in stage III and IV while non of positive CD49d cases where present in stage I. while those expressed negative CD $49 \mathrm{~d}(<30 \%)$ where significantly more in stage I, II $(p=0.015)$.

Demiralp et al., [17] and Gattei et al., [18] reported in their studies that patients in Rai stage 0, I and II had even lower CD49d expression than patients in Rai stage III and IV who had relatively higher levels of CD49d expression.

Zucchetto et al., [19] also stated that the adverse prognostic impact of CD49d expression is consistent with the demonstration of higher expression levels of CD49d in CLL cells from advanced stage patients.

On the contrary, Nuckel et al., found no association between high CD49d expression and advanced clinical stage.

This is in agreement with results done by Rossi et al., \& Cro et al., who reported that CD49d expression was associated with markers of rapid cell turn over namely high LDH.

In this study a statistically significant correlation between positive CD49d expression and CD38 was obtained, ( $p .021)$ patients with positive CD49d expression had significantly higher CD38 expression, which is powerly confirmed by Nuckel et al., who reported a highly significant correlation between CD49d and CD38, and considered CD49d expression as a powerful independent prognostic parameter.

Also Gattei et al., and Shanafelt et al., [20] reported strong correlation between CD49d expression and CD38 expression and suggested that simultaneous engagement of the two antigens could have a role in the protection of CLL cells against apoptotic stimuli. 
Zucchetto et al., [21] reported that Clinically, the combined analysis of CD49d and CD38 expression in CLL was demonstrated to worsen the negative prognostic information provided by any of the factors alone. Thus supporting the idea of a functional cooperation between these molecules usually co-expressed in CLL cell membranes.

Kurtova et al., [22] reported in CLL the phenotypic signature of positive CD49d is known to be associated with an adverse prognosis. In the present study stage 1 had no patients with positive CD49d while $42.9 \%$ of patients were in stage II and $28.6 \%$ of patients were in stage III and IV.

Bulian et al., [23] reported that high CD49d expression, are associated with shortened survival and poor response to chemotherapy.

These findings were explained by Shanafelt et al., who reported that positive CD49d categories do badly due to resistance to both spontaneous and chemotherapy induced apoptosis.

As regard NHL cases, this study showed a high significant difference between the NHL group and control as regard CD49d expression.

Based on cut off value of ( $>30 \%)$ of CD49d expression, this study showed (95\%) have positive CD49d expression, while only (5\%) of case has negative CD49d expression.

In agreement with Matos et al., [24] comparison of chronic lymphocytic leukemia and B-cell lymphoma showed that CLL cases presented a lower expression of CD49d. While the higher expression of adhesion molecule observed in marginal B-cell lymphoma is probably the result of the concomitant higher expression of CD49d.

In agreement with study of Kurtova et al., which showed all of the mantle cell lymphoma cell lines were strongly positive for CD49d.

Also this study showed that most NHL $(95 \%)$ expressed positive CD $49 \mathrm{~d}$ while only $58 \%$ of CLL expressed positive CD $49 \mathrm{~d}$ which is of statistically significant difference $(p<0.05)$.

\section{Conclusion:}

The present study confirmed that CD49d expression is a powerful prognostic parameter in patients with CLL. As it correlates with RAI stage, LDH level and CD38. So CD49d showed association with poor disease outcome in CLL patients.
Significant high expression of CD49 in NHL Thus CD49d is not specific for CLL. But it could be used as a prognostic marker.

\section{References}

1- XU W., LI J., WU Y., YU H., SHEN Q., LI L., FAN L. and QIU H.: Prognostic significance of ATM and TP53 deletions in Chinese patients with chronic lymphocytic leukemia. Leuk. Res., 32 (7): 1071-1077, 2008.

2- BYRD J.C., STILGENBAUER S. and FLINN I.W.: chronic lymphocytic leukemia. The American Society of Hematology Education Program Book, 4: 192. DD, 2004.

3- MAINOU-FOWTER T., PROCTOR S.J. AND SUMMER FIELD G.P.: The prognostic value of CD38 expression and its quantification in B-CLL. Leuk. Lymphoma 45 (3): 455-62, 2004.

4- NAWAKOWSKI S.G., HOYER J.D., SHANAYELT T.D. and ZENTC S.: Percentage of smudge cells on routine blood smears predicts survival in CLL 2009. J. Clin. Oncol., 27 (11): 1844-1849.

5- HSI E: The leukemias of mature lymphocytes. Hematol. Oncol. Clin. N. Am., 23: 843-871, 2009.

6- EICHHORST B., HALLEK M. and DREYLING M.: Chronic lymphocytic leukemia: ESMO Minimum Clinical Recommendations for diagnosis, treatment and followup: A report of ESMO Guidelines Working Group. Ann. Oncol., 4: 102-104, 2009.

7- HALLEK M., CHESON B., CATOVSKY D., CALIGARIS-CAPPIO F., DIGHIERO G., DÖHNER H., HILLMEN P., KEATING M.J., MONTSERRAT E., RAI K.R. and KIPPS T.: Guidelines for the diagnosis and treatment of chronic lymphocytic leukemia: A report from the International Workshop on Chronic Lymphocytic Leukemia updating the National Cancer Institute Working Group 1996 guidelines. Blood, 11 (12): 5446-5456, 2008.

8- JOHNSTON J., SEFTEL M. and GIBSON S.: Chronic lymphocytic leukemia. In: Wintrobe's Clinical Hematology, 12th edition. Greer J., Foesrster J., Lukens J., Rodgers G., Paraskevas F. and Glader B. (eds). Lippincott Williams and Wilkins Publishers, p. 2214, 2009.

9- ROSSI D., ZUCCHETTO A. and ROSSI F.M.: CD49d expression is an independent risk factor of progressive disease in early stage chronic lymphocytic leukemia. Haematologica, 93 (10): 1575-1579, 2009.

10- GATTEI V., BULIAN P. and DELPRINCIPE M.I.: Relevance of CD49d protein expression as overall survival and progressive disease prognosticator in CLL. Blood, 111: 865-73, 2008.

11-PIETRO B., GIANLUCA G., GIOVANNI P. and VALTER G.: CD49d expression in CLL: A prognostic parameter and a therapeutic target. Future. Oncology, 4 (3): 355358,2008 ,

12- MATUTES E. and POLLIACK A.: Morphological and immunophenotypic features of chronic lymphocytic leukemia. Rev. Clin. Exp. Hematol., 4 (1): 22, 2000.

13- BINET J., CALIGARIS-CAPPIO F., CATOVSKY D., CHESON B., DAVIS T. and DIGHIERO G.: Perspectives on the use of new diagnostic tools in the treatment of chronic lymphocytic leukemia. Blood, 107: 859-861, 2006. 
14- SHANAFELT T., GEYER S., BONE N., TSCHUMPER R., WITZIG T., NOWAKOWSKI G., ZENT C., CALL T., LAPLANT B., DEWALD G., JELINEK D. and KAY N.: CD49d expression is an independent predictor of overall survival in patients with chronic lymphocytic leukaemia: A prognostic parameter with therapeutic potential. British Journal of Haematology, 140: 537-546, 2008.

15-NUCKEL H., SWITALA M., COLLINS C., SELLMANN L., GROSSE-WILDE H., DÜHRSEN U. and REBMANN V.: High CD49d protein and mRNA expression predicts poor outcome in chronic lymphocytic leukemia. Clinical immunology, 1-9, 2009.

16- CRO L., GUFFANTI A., COLOMBI M., CESANA B., LANHAM S., HAMBLIN T. and PACKHAM G.: Differential signaling via surface IgM is associated with $\mathrm{VH}$ gene mutational status and CD38 expression in chronic lymphocytic leukemia. Blood, 101 : 1087-93, 2003.

17- DEMIRALP E., ALPDOGAN O., AKTAN M., FIRATLI T., OZTURK A., AKOGLU T. , BUDAK T. and BAYIK M.: Variable expression of CD49d antigen in B cell chronic lymphocytic leukemia is related to disease stages. Leukemia, 10: 1331-1339, 1996.

18- GATTEI V., BULIAN P. and DELPRINCIPE M.I.: Relevance of CD49d protein expression as overall survival and progressive disease prognosticator in CLL. Blood, 2008, 111: 865-73

19- ZUCCHETTO A., BOMBEN R., DAL BO M., BULIAN P., BENEDETTI D., NANNI P., DEL POETA G., DEGAN
M. and GATTEI V.: CD49d in B-cell chronic lymphocytic leukemia: correlated expression with CD38 and prognostic relevance. Leukemia, 20: 523-525, 2006.

20- SHANAFELT T., GEYER S., BONE N., TSCHUMPER R., WITZIG T., NOWAKOWSKI G., ZENT C., CALL T., LAPLANT B., DEWALD G., JELINEK D. AND KAY $\mathrm{N}$.: CD49d expression is an independent predictor of overall survival in patients with chronic lymphocytic leukaemia: A prognostic parameter with therapeutic potential. British Journal of Haematology, 140: 537-546, 2008.

21- ZUCCHETTO A., VAISITTI T., BENEDETTI D., TIS SINO E. and BERTAGNOLO V.: CD49/CD26 is physically and functionally associated with CD38 in B-CLL cells. Leukemia, 26 (6): 1301-1 307.

22- KURTOVA A., TAMAYO A., FORD R. and BURGER J.: Mantle cell lymphoma cells express high levels of CXCR4, CXCR5, and VLA-4 (CD49d): Importance for interactions with the stromal microenvironment and specific targeting. Blood, 113: 4604-4613, 2009.

23- BULIAN P., GAIDANO G., DEL POETA G. and GATTEI V.: CD49d expression in chronic lymphocytic leukemia: a prognostic parameter and a therapeutic target. Future Oncology, 4: 355-358, 2008.

24- MATOS D.M., RIZZATTI E.G., GARCIA A.B. and GALLO D.A.: Adhesion molecule profiles of B-cell nonHodgkin's lymphomas in the leukemic phase. Braz. J. Med. Biol. Res., 39 (10): 1349-1355, 2006. 


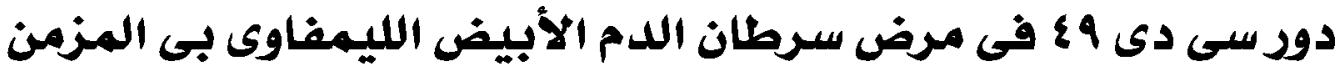

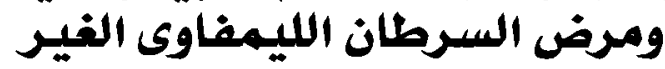 هوند}

يعتبر سرطان الدم الأبيض الليمفاوى المزمن خلال أحادى المنشاُ يتميز بتراكم خلايا ليمفاوية صغيرة من النوع (ب) فى الدم ونخاع العظم والأنسجة الليمفاوية.

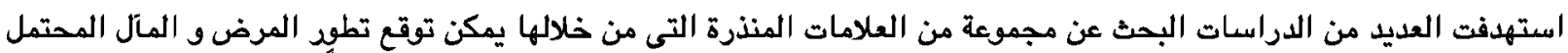

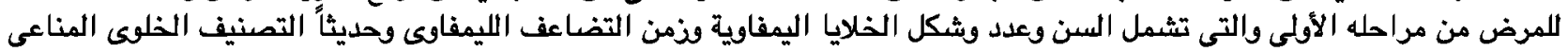
وفحص العينات الوراثية. ت الاولي

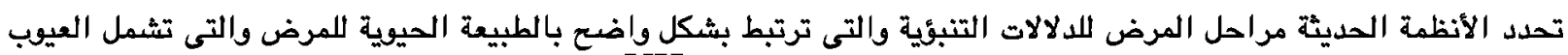

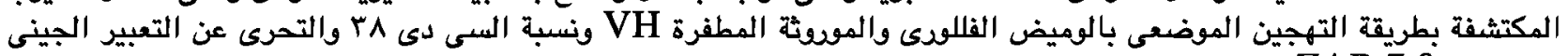

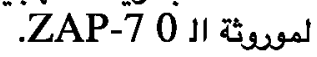

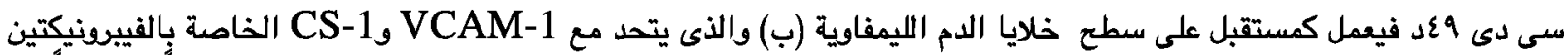

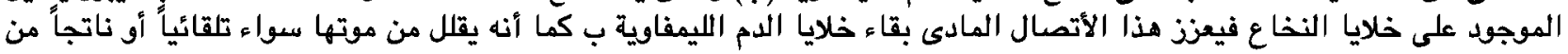
إستخدام الأدوية.

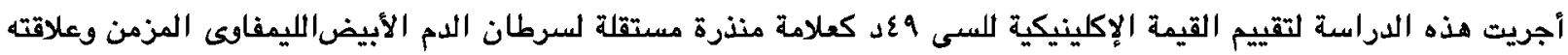

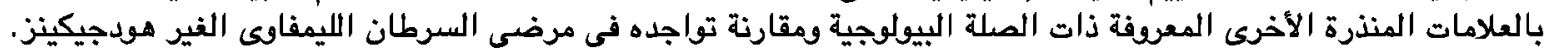

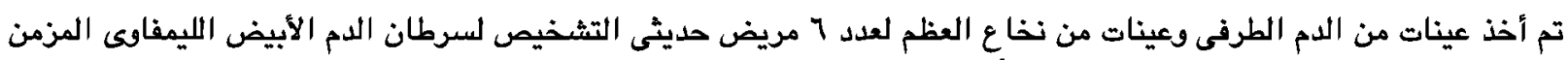

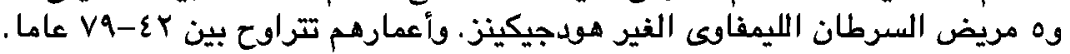

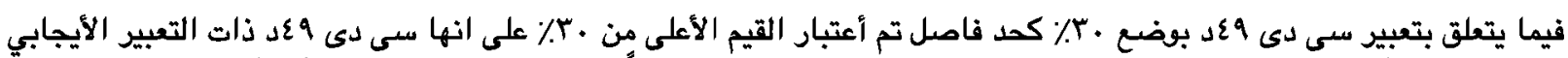

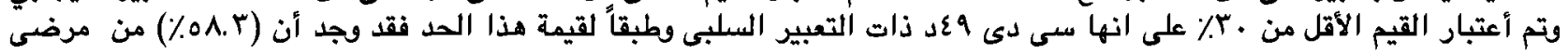

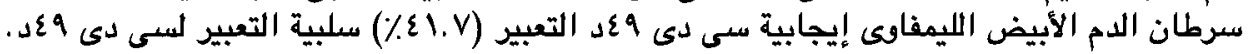

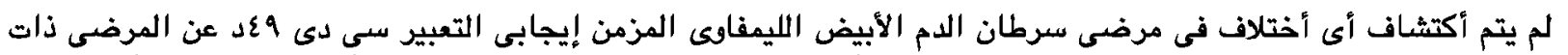

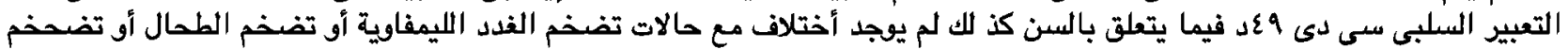

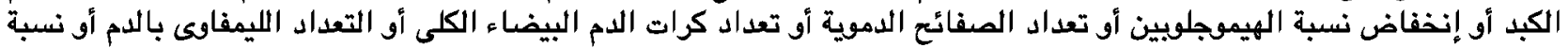

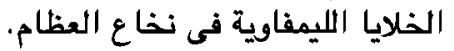

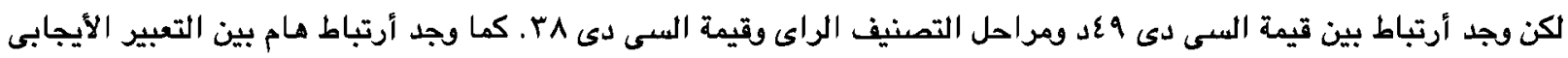

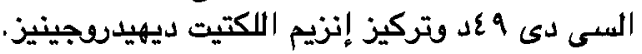

أما فيما يتعلق بمرضى السرطان الليمفاوى الغير هودجيكينز فقد وجد أختلاف هام بين تواجد 9 أد فى هذهالصالات عنها فى الأشخاص الأصحاء.

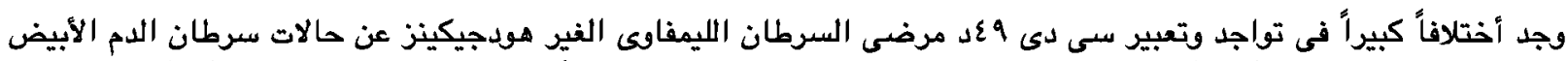

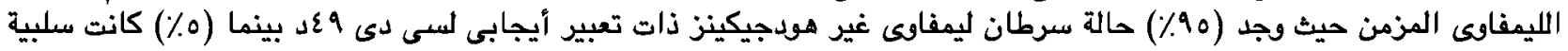

